\title{
AN EVALUATION OF ROMANIAN EDUCATION SYSTEM EFFICIENCY
}

\author{
Ionela-Cătălina ZAMFIR \\ Bucharest University of Economic Studies, Romania \\ ionela.zamfir@csie.ase.ro
}

\begin{abstract}
Assessing a system's efficiency is a challenge whatever the system is, due to the multitude of interactions within and between the systems. In this study, the input-output analysis of performance indicators is completed by data mining techniques in order to identify the position of Romanian education system on Europe's map. Principal components analysis $(P C A)$ is used to eliminate redundant information and create new variables that retain the essential information from initial variables (30 initial variables and 6 principal components), while k-means algorithm is used to classify 31 education systems from Europe in 3 efficiency classes. A preliminary analysis using few indicators show a highly efficient system for Romania (low financing rates and high employment rate with low risk of poverty or social exclusion), but mining deeply into the data and comparing Romania with other European countries show both the weak performance of the system and the way in which European countries are grouped on performance levels.
\end{abstract}

Keywords: assessment, education system, K-Means algorithm, principal components analysis JEL classification: $\mathrm{I} 21, \mathrm{C} 38$

DOI: $10.12948 / \mathrm{ie} 2019.03 .02$

\section{Introduction and literature review}

The evaluation of an entire system is an issue widely discussed nowadays, especially that modeling methods and techniques have evolved. A system represents a multitude of individuals that have certain characteristics, interact between them and with other individuals from other systems and have rules for making decisions. The education system is one of the most well governed systems, having well-established rules regarding the evaluation of outcomes efficiency. Modeling a system for assessing the efficiency suppose taking into account both input and output variables, as well as the interactions between the variables. The interest of researchers in this type of analyses can be seen as a concern of assessing the education systems (or parts of it). Demir [1] evaluate in 2013 the Turkish Education System taking into consideration interview data and using inductive descriptive analysis, content analysis ("the data were first divided into sections, and these sections were then compared with the investigation" - [1]) and constant comparison techniques. In 2017, Chakraborty et. all. [4] used a "multi-criteria decision-making (MCDM) framework utilizing preference ranking organization method" ([4]) to evaluate the performance of education system in India. Tseng et.all. [2] demonstrate in 2011 that fuzzy analytical network process have a high efficiency in analyzing the e-learning effectiveness, while in 2017, Kumar [5] used data for 151 teaching assistant and data mining methodologies to evaluate teacher's performance. The term "Educational Data Mining" (EDM) appeared as a necessity of extracting essential knowledge from big amount of data from education system. A recent review in this respect was made by Rodrigues et.all. ([3]) in 2018, when authors studied 72 articles that were grouped in several themes of interest. Another recent review about EDM (Villanueva Manjarres et.all [7]) show 
the use of data mining techniques in education, while Ranbaduge [6] propose using data mining to evaluate "the students overall performances in the e-learning systems" [6]. In this study, for assessing the Romanian education system efficiency is taken into consideration other European education systems. Principal components analysis reduces both dimensionality and redundant information, while cluster analysis classify the Romanian education system into a class of efficiency, comparing with other European countries. Section 2 details the methodologies and variables used, section 3 describes the results and discussions regarding the efficiency class for Romanian education system, while the last section presents the conclusions for this study, as well as further research.

\section{Methodologies and dataset}

Data mining techniques have evolved in the last decades as a response to the huge amount of data stored in the latest hardware technologies. Involving mathematics and statistics, as well as databases knowledge, these methods and techniques aim extracting knowledge from data.

After "cleaning" the collected data (some may replace missing data with the variable mean, in order to keep a certain observation in the dataset - in this case Iceland missing data for 3 variables were replaced by mean), the extraction of essential information is the next step. PCA represents a method for reducing the number of variables by creating new aggregated variables. The mathematical model for PCA is an optimization problem that maximizes the variance from variables that is retained in each principal component (PC). At each created component, by maximizing the variance taken from all variables, the redundant information is decreasing and PCs are uncorrelated. The classification methods allow grouping the countries in few efficiency classes. The number of classes is chosen by taking into account the analyzed issue. K-means algorithm is a method that group a number of observations into a known number of classes, considering the minimum distance between the observation and the mean of each class. In this way, the classes have observations with a high similarity inside each class, while the variability between classes is high. After choosing the number of classes and after assigning the initial observations to classes, the algorithm "runs" until each observations is assigned to one class. The dataset used to evaluate the Romanian education system is composed by 30 variables available for 2016 and 31 European countries, data provided by Eurostat [8]. The table from below show the variables used. The code for each indicator starts with $\mathrm{O}$ if is an output indicator, or I if is an input characteristic.

Table 1. Education system indicators

\begin{tabular}{|c|c|c|}
\hline \multicolumn{2}{|c|}{ Indicator name } & \multirow{2}{*}{$\begin{array}{c}\text { Indicator code } \\
\text { I_EXP_RESEARCH }\end{array}$} \\
\hline \multirow{6}{*}{$\begin{array}{c}\text { Total general } \\
\text { government } \\
\text { expenditure (\%GDP) } \\
\text { for }\end{array}$} & basic research & \\
\hline & education & I_EXP_EDUCATION \\
\hline & Pre-primary and primary education & I_EXP_PRIM \\
\hline & Secondary education & I_EXP_SEC \\
\hline & Tertiary education & I_EXP_TER \\
\hline & Subsidiary services to education & I_EXP_SUBSID \\
\hline \multirow{5}{*}{$\begin{array}{l}\text { Pupils and students (\% } \\
\text { of total age } \\
\text { population) in }\end{array}$} & Primary education & I_CHILD_PRIM \\
\hline & Upper secondary education & I_CHILD_UPP \\
\hline & Bachelor education & I_CHILD_BACH \\
\hline & Master education & I_CHILD_MAST \\
\hline & Doctoral education & I_CHILD_DOCT \\
\hline \multirow{2}{*}{$\begin{array}{l}\text { Participation rate in } \\
\text { education and training } \\
\text { last } 12 \text { months }(\%)\end{array}$} & total & I_PART_TRAIN \\
\hline & $\begin{array}{l}\text { Upper secondary and post-secondary } \\
\text { non-tertiary education }\end{array}$ & I_PART_SEC \\
\hline
\end{tabular}


www.conferenceie.ase.ro

\begin{tabular}{|c|c|c|}
\hline & Tertiary education & I_PART_TER \\
\hline \multirow{4}{*}{$\begin{array}{c}\text { Employment rate from } \\
15 \text { to } 74 \text { years }(\%)\end{array}$} & all ISCED 2011 levels & O_EMP_TOT \\
\hline & primary and lower secondary levels & O_EMP_PRIM \\
\hline & $\begin{array}{l}\text { upper secondary and post-secondary } \\
\text { non-tertiary levels }\end{array}$ & O_EMP_SEC \\
\hline & tertiary levels & O_EMP_TER \\
\hline \multirow{4}{*}{ Graduates (number) } & Upper secondary education & O_GRAD_UPP \\
\hline & Bachelor level & O_GRAD_BACH \\
\hline & Master level & O_GRAD_MAST \\
\hline & Doctoral level & O_GRAD_DOCT \\
\hline \multirow{4}{*}{$\begin{array}{c}\text { Employment rates of } \\
\text { people between } 15 \text { and } \\
34 \text { years }(\%)\end{array}$} & $\begin{array}{l}3 \text { years or less since completion of } \\
\text { highest level of education }\end{array}$ & O_LESS3Y_TOT \\
\hline & $\begin{array}{l}\text { over } 3 \text { years since completion of } \\
\text { highest level of education }\end{array}$ & O_OVER3Y_TOT \\
\hline & $\begin{array}{l}3 \text { years or less since completion of } \\
\text { Tertiary education }\end{array}$ & O_LESS3Y_TER \\
\hline & $\begin{array}{l}\text { over } 3 \text { years since completion of } \\
\text { Tertiary education }\end{array}$ & O_OVER3Y_TER \\
\hline \multirow{4}{*}{$\begin{array}{l}\text { People over } 18 \text { years } \\
\text { at risk of poverty or } \\
\text { social exclusion }(\%)\end{array}$} & total & O_POV_TOT \\
\hline & levels $0-2$ of education & O_POV_PRIM \\
\hline & levels 3-4 of education & O_POV_SEC \\
\hline & levels 5-8 of education & O_POV_TER \\
\hline
\end{tabular}

\section{Results and discussions}

The dataset presented in the above section was split in two datasets: one for input variables (14 indicators) and another for output variables (16 indicators).
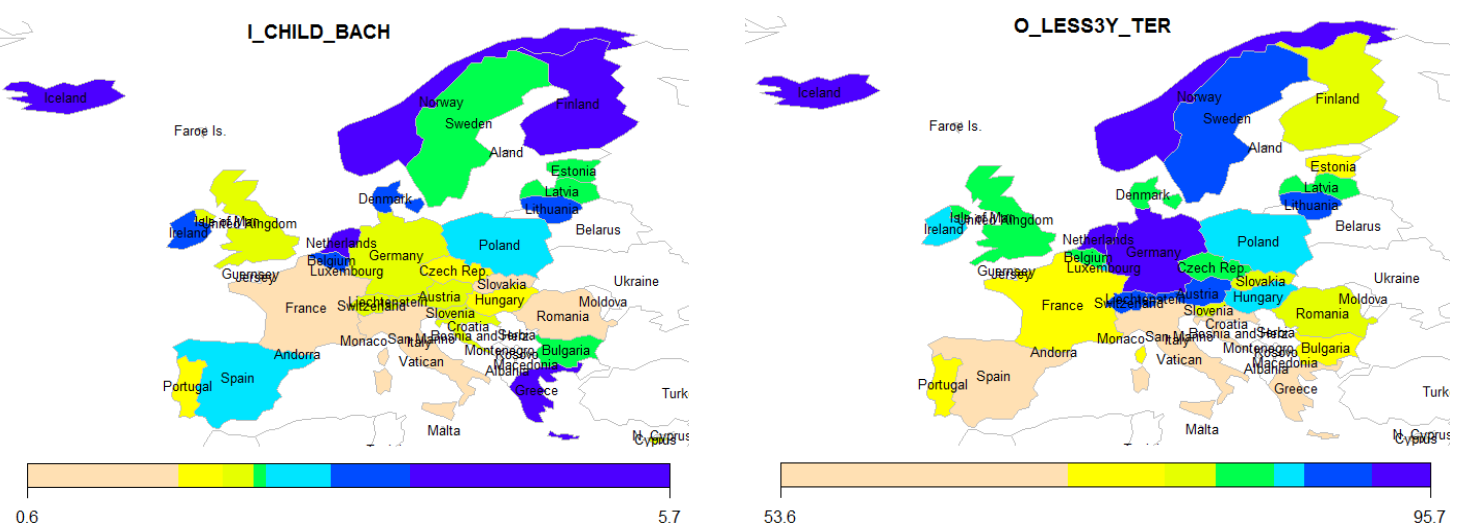

Figure 1. European maps representing I_CHILD_BACH and O_LESS3Y_TER

The figure from above show a comparison between the percent of students (from total age population) in bachelor education (I_CHILD_BACH) and the percent of people between 15 and 34 years that hired in 3 years or less since completion of tertiary (bachelor, master or doctoral) education (O_LESS3Y_TER). Bulgaria, Spain and Finland have over $2.5 \%$ of students in bachelor education (Romania have 1.8\%, Finland have 3.9\%), while the employment rate for Bulgaria is $77.2 \%, 70.8 \%$ for Spain and $80.6 \%$ for Finland, lower or comparable with a Romanian level of $79.9 \%$. This could show that Romanian education system have a higher efficiency rate than Bulgaria, Spain or even Finland, since more young people with tertiary education find a job in the first 3 years after completion their studies. 


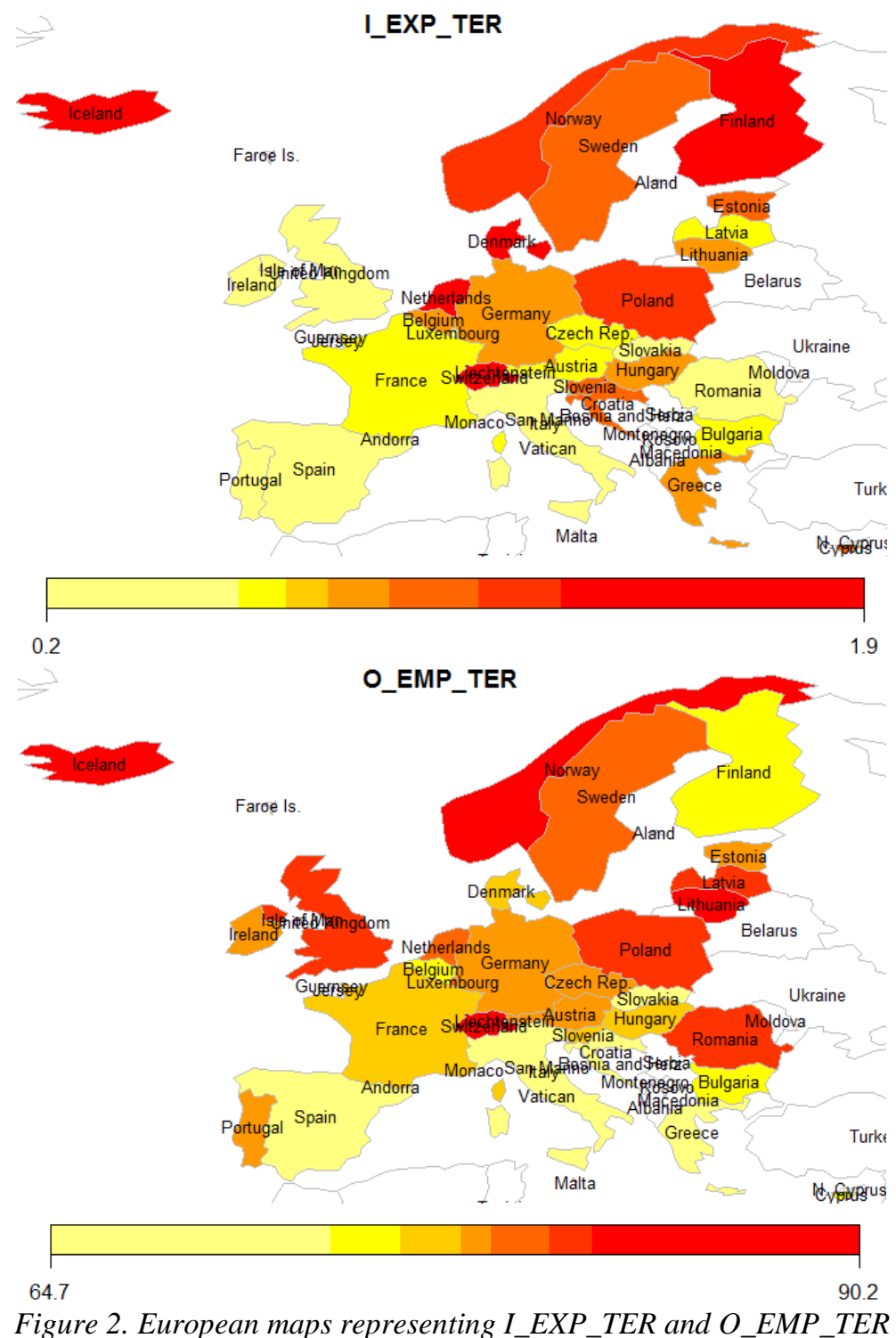

Another set of input-output indicators that show the efficiency of Romanian education system is the comparison between the total general government expenditure (as \% of GDP) for tertiary education (I_EXP_TER) and the employment rate for people from 15 to 74 years with tertiary education (O_EMP_TER), like in figure from above (maps were created in R). Countries like Denmark (1.7\% of GDP), Netherlands (1.4\% of GDP), Poland (1.2\% of GDP) or Finland (1.9\% of GDP) have higher expenditure rates for tertiary education than Romania ( $0.6 \%$ of GDP), but lower employment rates (77.4\% Denmark, 80.3\% Netherlands, $81 \%$ Poland and $73.7 \%$ Finland) than Romania (81.6\%), that could represent the idea that Romanian education system is more efficient with less money than other developed economies. But, in order to provide a consolidated view about the efficiency level of Romanian education system, comparing to other European education systems, it is necessary to analyze the entire dataset. 


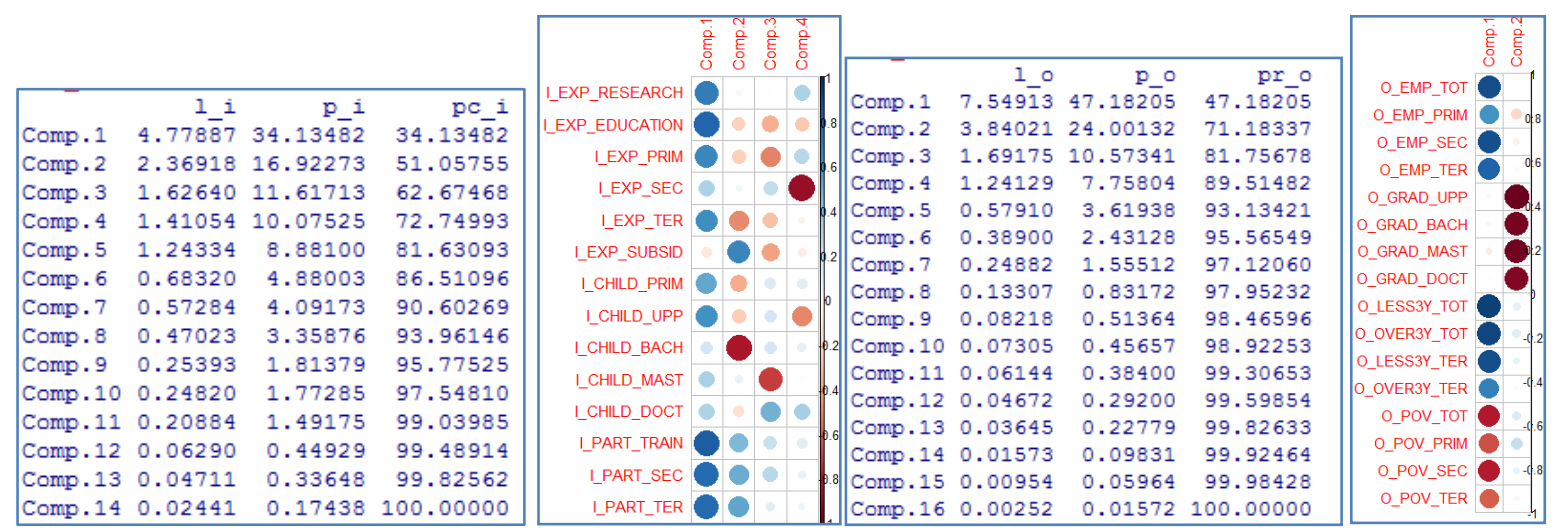

Figure 3. Principal components analysis results for input and output datasets

The figure from above represents the output of PCA for input (first two figures) and output (last two figures) indicators datasets. This type of analysis provides aggregate indicators that can describe better the efficiency of the system. Therefore, 4 aggregates (that retain almost $73 \%$ of total information from input indicators dataset) were selected from 14 variables in input dataset, and 2 aggregates (retaining $71 \%$ of information) for output dataset. According to the correlations between initial variables and principal components (PC), presented in the figure from above, the new variables were named like: expenditures, children and adult education (I_EXT_ADED), subsidiary and students in bachelor education (I_SUB_BACH), students in master and doctoral education (I_MD), expenditures in secondary education (I_EXCH_SEC), employment rate and poverty (O_EMP_POV) and graduates (O_GRAD).

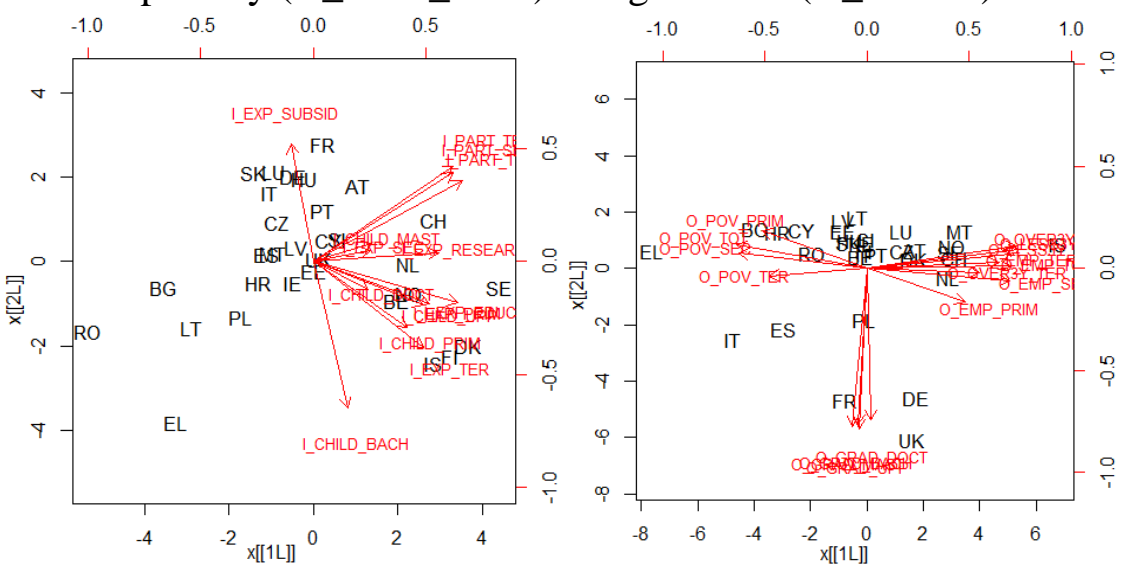

Figure 4. Biplots for first 2 principal components of each dataset

Using the new variables named above it is possible to describe better the education system in terms of relation input-output and other European systems. A high value for I_EXP_ADED (countries like Sweden, Finland, Denmark, Iceland, Belgium or Netherlands) show high values for government expenditure, pupils and students in primary and upper secondary education and adult education (described by participation rate in education and training in the last 12 months), because the first PC from input dataset is high and positive correlated with these variables. Low values for this variable (like Romania, Bulgaria, Greece or Lithuania) prove low inputs for education, especially adult education and government expenditures. Low values for O_EMP_POV (like Greece) show high risk of poverty or social exclusion (negative correlations between poverty risk variables and first PC from output dataset) and a low employment rate. In this case, Romania is close to Spain, France, Hungary or Cyprus, while from the point of view of number of graduates from upper secondary and tertiary education, 
the highest values are for France, UK, Germany (negative correlations between number of graduates and second PC from output dataset - O_GRAD).

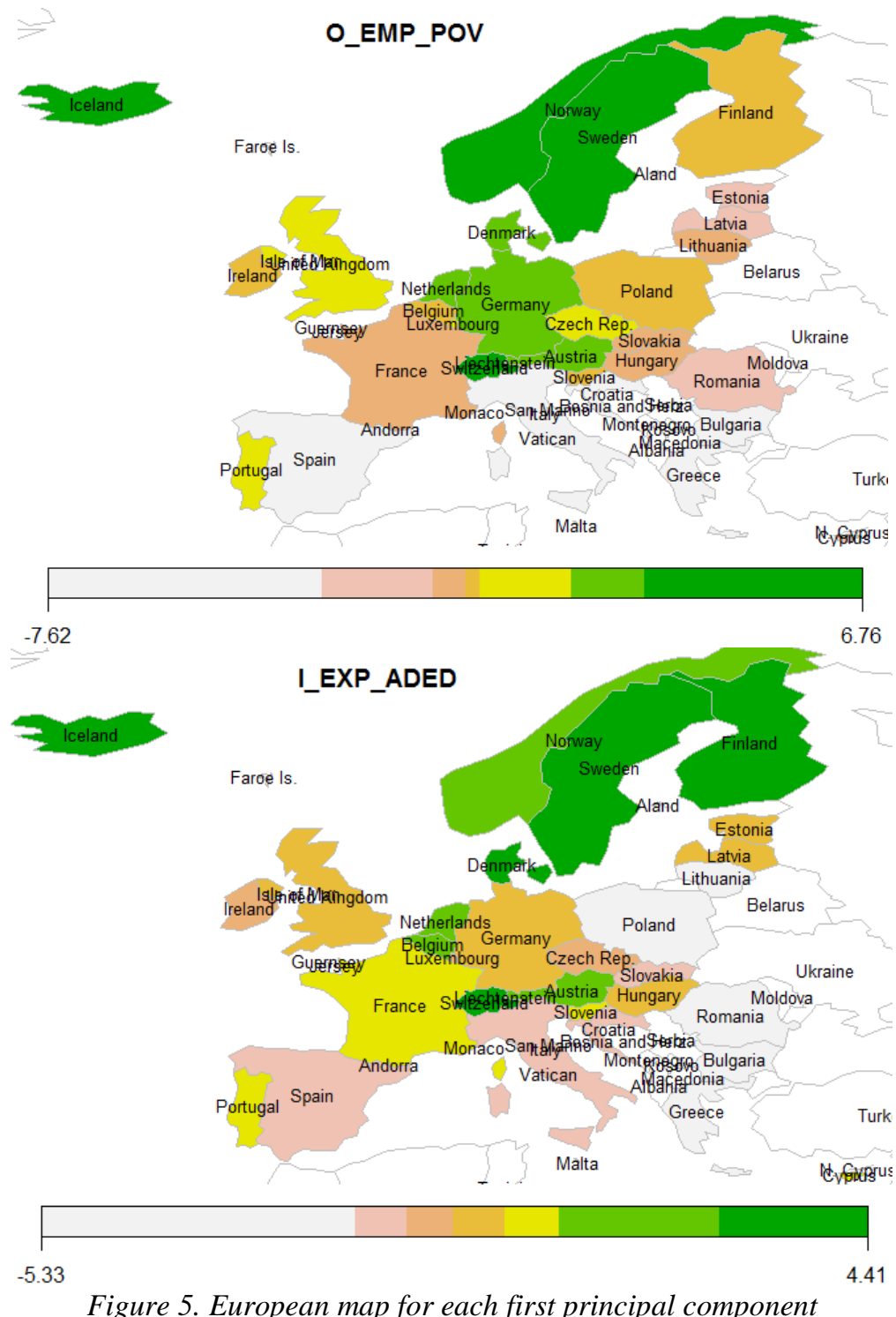

The maps from above show the same assessment of Romanian education. From input point of view (image from right side), Romania has among the lowest financing rates and the interest shown for education is poor, while the system output in terms of employment rate (high) and poverty rate (low) is better than other countries that invest more in education.

$\begin{array}{crcrrrr} & \text { O_EMP_POV } & \text { O_GRAD I_EXP_ADED } & \text { I_SUB_BACH } & \text { I MD } & \text { I_EXCH_SEC } \\ 1 & 2.8962 & 0.4623 & 3.0820 & -1.0142 & 0.0730 & 0.2183 \\ 2 & -3.5460 & 0.1422 & -2.6491 & -0.9139 & -0.0091 & 0.1605 \\ 3 & 0.2676 & -0.2489 & -0.1783 & 0.7939 & -0.0263 & -0.1560 \\ \text { Figure 6. Classes centroids } & \end{array}$

K-means algorithm applied on PC described above leads to a classification of selected countries into 3 classes of efficiency. The meaning of each PC and the classes centroids (figure from above) give a significance and a description for each class: the first class is characterized by a good employment rate, low poverty risk, a relatively small number of graduates, high financing 
rates and adult interest for education and could represent a class for efficient education system; the second class has the lower efficiency rate, being (in average) the opposite of the first class, while the third class have a middle efficiency rate.

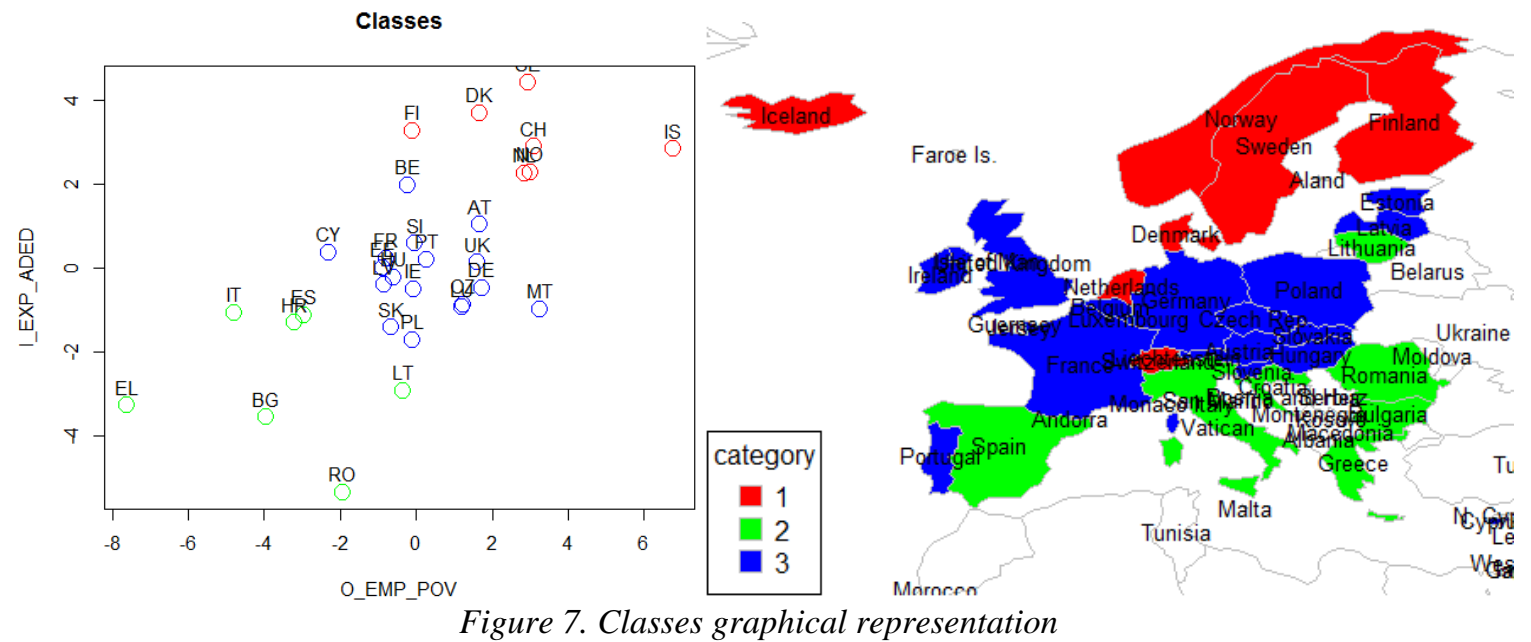

The figure from above show the graphically representation for classes: the first image takes into account the first PC from datasets, while the map show the three European layers of education system efficiency. It is interesting to discover that Europe countries are grouping in three layers, starting with a low (in average) efficiency rates for education systems for south countries, average efficiency rates for center countries and highest rates for north countries.

\section{Conclusions and further research}

This research represents an overview assessment of Romanian education system, comparing with European education system using available data for 2016. Taking into consideration a separate component of the system (input or output variable) might show that Romanian education system has a high performance and efficiency rate, but an overview of the entire datasets prove a contrary opinion. It must be specified the fact that this research does not take into account the specificity of each education system (that might not be quantified) and do not question the fact that employment rates for tertiary education graduates represent finding a job strongly correlated with the field of study. The idea of "mining" deeply into the area of assessing a system with other methodologies (like DEA) represents the further research.

\section{References}

[1] Demir, Selçuk., "Evaluation of the new education system by social studies teachers", Educational Research and Reviews, vol. 8, no. 17, pp. 1525-1532, 2013.

[2] M.L. Tseng, R.J. Lin, H.P. Chen, "Evaluating the effectiveness of e-learning system in uncertainty", Industrial Management \& Data Systems, vol. 111, no. 6, pp.869-889, 2011.

[3] M. Rodrigues, L. Zárate, S. Isotani, "Educational Data Mining: A review of evaluation process in the e-learning", Telematics and Informatics, 10.1016/j.tele.2018.04.015, 2018

[4] S. Chakraborty, D. Paul, P. K. Agarwal, "Evaluation of educational performance of Indian states using PROMETHEE-GIS approach", Benchmarking: An International Journal, vol. 24 no. 6, pp.1709-1728, 2017.

[5] Surjeet Kumar, "A Modern Data Mining Method for Assessment of Teaching Assistant in Higher Educational Institutions", International Journal of Computer Science and Information Technologies (IJCSIT), vol. 8, no. 3, pp. 424-429, 2017. 
www.conferenceie.ase.ro

[6] Thilina Ranbaduge," Use of Data Mining Methodologies in Evaluating Educational Data", International Journal of Scientific and Research Publications, vol. 3, no. 11, November 2013, ISSN 2250-3153

[7] Villanueva Manjarres, A.V., Moreno Sandoval, L.G., Salinas Suárez, M.J., "Data mining techniques applied in educational environments: Literature review", Digital Education Review, no. 33 pp. 235-266, 2018.

[8] Eurostat - Database. [Online]. Available: https://ec.europa.eu/eurostat/data/database, [Accessed March 15-16, 2019]. 